\title{
Biochemical and Molecular Characterization of Carotenogenic Flavobacterial Isolates from Marine Waters
}

\author{
RAMA SOWMYA and NAKKARIKE M. SACHINDRA* \\ Department of Meat and Marine Sciences, CSIR-Central Food Technological Research Institute \\ Mysore, India
}

Submitted 9 January 2015, revised 15 April 2015, accepted 19 April 2015

\begin{abstract}
Carotenoids are known to possess immense nutraceutical properties and microorganisms are continuously being explored as natural source for production of carotenoids. In this study, pigmented bacteria belonging to Flavobacteriaceae family were isolated using kanamycincontaining marine agar and identified using the molecular techniques and their phenotypic characteristics were studied along with their potential to produce carotenoids. Analysis of random amplification of polymorphic DNA (RAPD) banding patterns and the fragment size of the bands indicated that the 10 isolates fall under two major groups. Based on $16 \mathrm{~S}$ rRNA gene sequence analysis the isolates were identified as Vitellibacter sp. (3 isolates), Formosa sp. (2 isolates) and Arenibacter sp. (5 isolates). Phenotypically, the isolates showed slight variation from the reported species of these three genera of Flavobacteriaceae. Only the isolates belonging to Vitellibacter and Formosa produced flexirubin, a typical yellow orange pigment produced by most of the organisms of the family Flavobacteriaceae. Vitellibacter sp. and Formosa sp. were found to produce higher amount of carotenoids compared to Arenibacter sp. and zeaxanthin was found to be the major carotenoid produced by these two species. The study indicated that Vitellibacter sp. and Formosa sp. can be exploited for production of carotenoids, particularly zeaxanthin.
\end{abstract}

Ke y w o r d s: Arenibacter sp., Flavobacteriaceae, Formosa sp., Vitellibacter sp., carotenoid, zeaxanthin

\section{Introduction}

Carotenoids are very widely distributed in nature, where they play an important role in protecting cells and organisms against the harmful effects of radicals. The primary mechanism of action is the ability of carotenoids to quench excited sensitizer molecules and quench singlet oxygen. Carotenoids can also serve as antioxidants under conditions other than photosensitization (Krinsky, 1989). Carotenoids from marine resources are known to possess various health beneficial activities (Sowmya and Sachindra, 2011).

Bacteria belonging to the phylum Cytophaga-Flavobacterium-Bacteroides (CFB) are common inhabitants of marine environments. Several Flavobacterium species are pathogenic to fish and invertebrates. Flavobacterium columnare causes columnaris disease (Decostere, 2002), and Flavobacterium psychrophilum causes infections in salmonid fish (Nematollahi et al., 2003). Flavobacteria are characterized by their pigmentation properties, which is due to production of carotenoids. Zeaxanthin is the predominant carotenoid synthesized biologically by few species of the genus Flavobacterium (Johnson and Schroeder, 1995). Among the carotenoids present in the body, only lutein, zeaxanthin and mesozeaxanthin, are found in the macula lutea of the eye. Lutein and zeaxanthin provide significant protection against the potential damage caused by light as reported in many studies (Bone et al., 2007; Roberts et al., 2009). It is also suggested that zeaxanthin is protective against age-related increase in lens density and cataract formation (Sajilata et al., 2008). Liver carcinogenesis in $\mathrm{C} 3 \mathrm{H} / \mathrm{He}$ male mice was suppressed when fed with zeaxanthin mixed as an emulsion (Nishino et al., 1999). Zeaxanthin plays an important role in the inhibition of macrophage-mediated LDL oxidation suggesting that it might help in slowing atherosclerosis progression (Carpenter et al., 1997).

Much emphasis has been laid on the pathogenic Flavobacteria, but very little importance is given to the beneficial aspects of other bacteria belonging to Flavobacteriaceae. It has been reported that Flavobacteria produces not only zeaxanthin but also others carotenoids. Rählert et al. (2009) identified three carotenogenic

\footnotetext{
* Corresponding author: N.M. Sachindra, Department of Meat and Marine Sciences, CSIR-Central Food Technological Research Institute, Mysore, India; e-mail: nmsachindra@cftri.res.in
} 
genes from Flavobacterium P99-3 that produces myxol, a monocyclic carotenoid and reported that $\operatorname{crtA}$ gene encodes for a novel carotenoid 2-hydroxylase involved in myxol biosynthesis which is highly homologous to crtA from purple bacteria encoding an acyclic carotenoid 2-ketolase. Another marine myxol-producing bacteria Robiginitalea myxolifaciens strain YM6-073 belonging to the Flavobacteriaceae have been isolated (Manh et al., 2008). Saproxanthin and myxol isolated from Flavobacteriaceae are monocyclic carotenoids rarely found in nature and have antioxidative activities against lipid peroxidation in the rat brain homogenate model and neuro-protective effect from L-glutamate toxicity (Shindo et al., 2007).

Eventhough, many new genera of CFB are described in the literature, their biochemical and molecular characterization is lacking, particularly the aspect of carotenoid production. In this study, the emphasis was given to the characterization of bacteria of the Flavobacteriaceae family from the Indian marine environment and carotenoid produced by them.

\section{Experimental}

\section{Materials and Methods}

Media and chemicals. Zobell marine broth, Zobell marine agar, Hi-carbokit and other media components were procured from Hi-Media Pvt. Limited. Mumbai, India. PCR components, lysozyme and primers were from Sigma-Aldrich, India. Solvents and analytical grade chemicals were from SRL, India. Flavobacterium sp. (MTCC 4664) was obtained from IMTECH, Chandigarh, India.

Selective isolation of bacteria of Flavobacteriaceae family. Samples of marine sediment, water from different depths, seaweeds and sponges were collected from different regions of East and west coast of India (Tuticorin, Mandappam, Rameshwaram and Mangalore). A selective marine agar medium containing kanamycin was used for isolation and enumeration of yellow-pigmented colonies by modified method of Flint (1985). Zobell marine broth containing kanamycin at 50 micrograms $/ \mathrm{ml}$ concentration was used for isolation of bacteria from marine water and sediments samples. After incubation for $24 \mathrm{hrs,} \mathrm{a} \mathrm{loopful} \mathrm{of} \mathrm{sam-}$ ple was streaked onto marine agar plates containing kanamycin $(50 \mu \mathrm{g} / \mathrm{ml})$. Colonies showing the yelloworange pigmentation were isolated and purified by repeated streaking.

Biochemical characterization. Biochemical tests performed include gram staining, motility test, oxidase activity, catalase production, deamination of L-tryptophan, decarboxylation of indole, MR-VP, oxidation and fermentation of sugars. Utilization of glucose, mannitol, inositol, sucrose and other 31 sugars was assessed by using Hi-carbo kit. Hydrolysis of esculin, gelatin and starch were also performed using standard techniques. Growth in marine broth at different temperatures of $10^{\circ} \mathrm{C}, 25^{\circ} \mathrm{C}, 37^{\circ} \mathrm{C}$ and $50^{\circ} \mathrm{C}$, at different $\mathrm{pH}$ of 4,7 and 10 were performed to characterize the growth of organisms. Flexirubin production by the isolates was tested by the method of Fautz and Reichenbach (1980). Haemolytic activity of the cultures was tested using blood agar. Antibiotic sensitivity of the isolates was tested by the method of Bauer et al. (1966).

Scanning Electron Microscopic (SEM) analysis. Morphological analysis of the culture isolates were performed according to the method of McDougall et al. (1994). Briefly, selected isolates grown in marine broth were centrifuged, washed thrice with phosphate buffer saline ( $\mathrm{pH} 7.0)$ to remove salts, fixed with glutaraldehyde $(2 \%)$ and subjected to gradual alcoholic dehydration. The processed samples were then analyzed on SEM (Leo-435 VP, Leo Electron Microscope, Zeiss Ltd., Cambridge, UK).

Random Amplification of Polymorphic DNA (RAPD). Genomic DNA was extracted from the bacterial isolates using the standard DNA isolation protocol (Sambrook and Russell, 2001). Random amplification of polymorphic DNA (RAPD) was performed using M13 primer (5'-GAGGGTGGCGGTTCT-3') for microbial typing according to Schillinger et al. (2003) and the product was run on $1.8 \%$ agarose gel. RAPD banding pattern was further analyzed using GeneSys ${ }^{\otimes}$ software (SYNGENE, UK) and the similarity of the band profiles and the grouping of the RAPD-PCR patterns were calculated based on the Pearson's coefficient and agglomerative clustering with unweighted pairs group matching algorithm (UPGMA), and the dendrogram was constructed using GeneSys ${ }^{\circledast}$ software.

16S rRNA gene sequencing and phylogenic analysis. 16S rRNA gene was amplified using the universal bacterial forward and reverse primers $27 \mathrm{~F}$ (5'-AGAGTTTGATCCTGGCTCAG-3') and 1492R (51-GGTTACCTTGTTACGACTT-31) respectively. Each PCR mixture of $25 \mu$ contained template DNA $(20 \mathrm{ng} / \mu \mathrm{l}), 0.2 \mu \mathrm{M}$ of each primer, $0.25 \mathrm{mM}$ of each deoxynucleoside triphosphate (dNTP), and $2.5 \mathrm{U}$ of TaqDNA polymerase in a final concentration of $10 \mathrm{mM}$ Tris- $\mathrm{HCl}, 50 \mathrm{mM} \mathrm{KCl}$, and $1.5 \mathrm{mM} \mathrm{MgCl}$. PCR was performed under the following cycle conditions: an initial denaturation step at $94^{\circ} \mathrm{C}$ for $5 \mathrm{~min}$ and 35 cycles of denaturation at $94^{\circ} \mathrm{C}$ for $30 \mathrm{~s}$, annealing at $55^{\circ} \mathrm{C}$ for $2 \mathrm{~min}$, and extension at $72^{\circ} \mathrm{C}$ for 2 mins. A final extension step at $72^{\circ} \mathrm{C}$ for $10 \mathrm{~min}$ was performed. The PCR product of $1.4 \mathrm{~kb}$ was purified and sequenced at Amnion Biosciences, Bangalore, India. The $16 \mathrm{~S}$ rRNA gene sequences obtained was subjected to nBLAST 
for similarity identification. Multiple alignment and sequence similarity with that of available sequences of reference strains from GenBank database were analyzed using CLUSTAL X. The phylogenetic tree was constructed using the MEGA 4 program (Biodesign Institute, Tempe, AZ, USA) by the method of neighborjoining (Kumar et al., 2008). The sequences have been deposited at NCBI GenBank.

Whole-cell protein analysis. Whole-cell protein extracts were prepared by suspending the culture pellet in phosphate buffer saline ( $\mathrm{pH}$ 7.0) and sonicating at $150 \mathrm{~W}$ power until the suspension is clear (Chart, 1994). Sodium dodecylsulfate polyacrylamide gel electrophoresis (SDS-PAGE) of the whole-cell protein extracts was performed with a $12 \%$ gel by the procedure of Laemmli (1970) and run at a constant current of $16 \mathrm{~mA}$, stained overnight with coomassie brilliant blue R-250 and following destaining the electrophoretic patterns were scanned with a gel documentation system (G-Box, SYNGENE, UK) and cluster analysis of electrophoretic patterns was done by the software GeneSys . A dendrogram representing the relationship between all strains tested was derived from the TREE option. The whole-cell protein patterns of the 10 isolates and standard culture were compared.

Extraction and characterization of carotenoids. The bacterial isolates were inoculated into $50 \mathrm{ml}$ marine broth and grown for 5 days at $37^{\circ} \mathrm{C}$ under shaking condition $(200 \mathrm{rpm})$ and the cells were harvested by centrifuging at $8000 \mathrm{rpm}$ for $15 \mathrm{~min}$. Cells were suspended in sterile saline and lysed by adding the lysozyme $(20 \mathrm{mg} / \mathrm{ml})$. Carotenoids were extracted by homogenizing the lysed cell suspension with acetone, filtered, and cells re-extracted with fresh acetone. The acetone extract was pooled and subjected to phase separation with equal quantity of hexane. The hexane extract was dried with sodium sulphate to remove traces of water if any, filtered and then evaporated under vacuum at $40^{\circ} \mathrm{C}$ using a rotary flash evaporator and flushed with nitrogen to obtain the total carotenoid extract. The yield of recovered carotenoid was determined.

Thin layer chromatography (TLC) of carotenoid extract from selected isolates was performed using Silica Gel 60 plates (MERCK). The samples along with standard carotenoids and plates were developed using the mobile phase of acetone: hexane (75:25). Then, HPLC of the extracted carotenoids was done by C18 TSK gel ODS-80TS column $(4.6 \mathrm{~mm} \mathrm{ID} \times 25 \mathrm{~cm})$ with gradient run of 35 min with solvent $A$ as methanol and water (95:5) and solvent $B$ as methanol and tetrahydrofuran (7:3) with a flow rate of $1.25 \mathrm{ml} / \mathrm{min}$ at $470 \mathrm{~nm}$ using a diode array detector.

Statistical analysis. Mean values of yield of crude carotenoid extract and zeaxanthin content in the carotenoid extract were subjected to ANOVA to determine the effects, and mean differences observed were subjected to Duncan's multiple range test using the software STATISTICA (Statsoft, 1999).

\section{Results and Discussion}

Isolation and characterization of carotenoidproducing bacteria. Pigmented colonies were selected from the marine agar plates containing the kanamycin and were purified. In all 10 isolates from different location and source were selected for further study based on pigmentation, source and location (Table I). The color of the selected isolates was yellow-orange to dark orange, and all the isolates had a slimy surface. The 10 selected cultures along with the standard culture Flavobacteria sp. MTCC 4664 had distinct RAPD banding patterns, and the fragment size of the bands ranged from 250 to $2370 \mathrm{bp}$. According to the dendrogram (Fig. 1) and cluster analysis, the isolates were grouped into two major groups, wherein isolates KW1, KW2, SUW, $4 \mathrm{~W}$ and $7 \mathrm{~W}$ were in one group and the other 5 isolates along with MTCC 4664 were in the other group.

Table I

Details of isolates

\begin{tabular}{|l|l|l|l|}
\hline \multicolumn{1}{|c|}{ Isolate } & \multicolumn{1}{c|}{ Source } & \multicolumn{1}{c|}{ Location } & Colony characteristics \\
\hline BW & Sea water (beach side) & $13.87^{\circ} \mathrm{N}, 74.63^{\circ} \mathrm{E}$ & Dark orange, slimy \\
\hline C12 & Sea water $(12$ meter depth) & $12.57^{\circ} \mathrm{N}, 74.47^{\circ} \mathrm{E}$ & Dark orange, slimy \\
\hline NMW & Mangrove water & $12.80^{\circ} \mathrm{N}, 74.85^{\circ} \mathrm{E}$ & Dark orange, slimy \\
\hline MBW & Sea water (beach side) & $13.35^{\circ} \mathrm{N}, 74.70^{\circ} \mathrm{E}$ & Orange, slimy \\
\hline KMW & Mangrove water & $13.21^{\circ} \mathrm{N}, 75.02^{\circ} \mathrm{E}$ & Orange, slimy \\
\hline 4W & Sea water (beach side) & $08.53^{\circ} \mathrm{N}, 78.36^{\circ} \mathrm{E}$ & Yellow orange, slimy \\
\hline 7W & Sea water (beach side) & $08.48^{\circ} \mathrm{N}, 78.12^{\circ} \mathrm{E}$ & Yellow orange, slimy \\
\hline KW1 & Sea water (beach side) & $13.49^{\circ} \mathrm{N}, 74.70^{\circ} \mathrm{E}$ & Yellow orange, slimy \\
\hline KW2 & Sea water (beach side) & $13.49^{\circ} \mathrm{N}, 74.70^{\circ} \mathrm{E}$ & Yellow orange, slimy \\
\hline SUW & Sea water (beach side) & $12.98^{\circ} \mathrm{N}, 74.78^{\circ} \mathrm{E}$ & Yellow orange, slimy \\
\hline
\end{tabular}




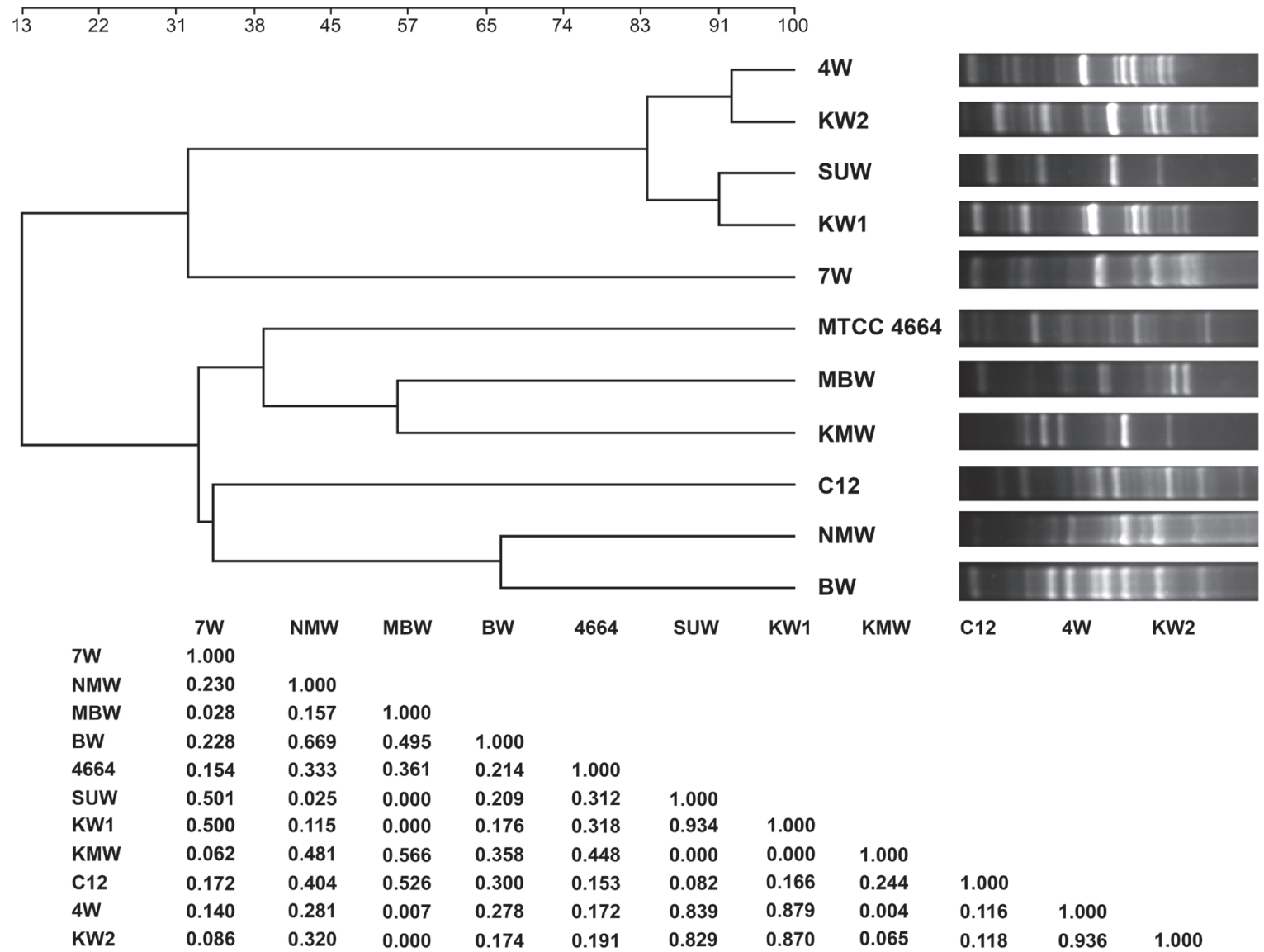

Fig. 1. Dendrogram drawn using RAPD profile of bacterial isolates.

UPGMA bootstrapping values of this clade were 95-99. Culture isolates were grouped by considering the significances in bootstrap values, interior branch lengths, and diversification rate.

The second group consisted of three subgroups having isolates NMW and BW in one subgroup and $\mathrm{C} 12$, KMW and MBW in another subgroup, with MTCC 4664 being a separate subgroup.

The whole-cell protein patterns of the 10 isolates with the standard culture had a major protein band patterns ranging from $18 \mathrm{kDa}$ to $116 \mathrm{kDa}$. Heterogeneity in SDS-PAGE protein patterns among different isolates was clearly observed. A dendrogram was created based on the electrophoretic pattern and is depicted in Fig. 2. Two major groups were formed based on SDS-PAGE patterns of whole cell protein, where the isolates MBW, KMW along with MTCC 4664 isolates formed one group and the rest being in the other group. Among the 8 isolates in the second group, a high similarity of 0.891 was observed between the isolates SUW and KW1.

The selected isolates were identified by $16 \mathrm{~S}$ rRNA gene amplification. The $16 \mathrm{~S}$ rRNA gene products were sequenced, and the sequences were used for database query. The nucleotide sequence data has been deposited at the National Center for Biotechnology Information (NCBI). The 16S rRNA gene sequences were subjected for BLAST using the megablast tool of GenBank (http:// www.ncbi.nlm.nih.gov/), which revealed that the iso- lates belonged to three genera of Flavobacteriaceae, namely, Formosa, Vitellibacter and Arenibacter. The isolates under genus Arenibacter along with their GenBank accession number are Arenibacter sp. SUW (KJ658267), Arenibacter sp. KW1 (KJ658268), Arenibacter sp. 4W (KJ658269), Arenibacter sp. KW2 (KJ658270) and Arenibacter sp. 7W (KJ658274). The three Vitellibacter strains are Vitellibacter sp. C12 (KJ658271), Vitellibacter sp. NMW (KJ658275), Vitellibacter sp. BW (KC888001) and the two Formosa strains were Formosa sp. KMW (KC888002) and Formosa sp. MBW (KC888003).

Representatives of maximum homologous (98-99\%) sequences of each isolate and other members of the Flavobacteria family like Aequorivita, Olleya, Yeosuana, Lacinutrix and Flexibacter were obtained from NCBI GenBank and were used for the construction of a phylogenetic tree which is rooted where a common ancestor is defined. All the 5 Arenibacter isolates were found to be grouped along with Arenibacter latericius, Arenibacter certessi and Flexibacter aggregans. All three Vitellibacter isolates were in a group with Vitellibacter vladivostokensis and Aequorivita sp., while Formosa isolates were in the group comprising of Oleya sp., Yeosuna sp., Gaelibulibacter sp., Gelidibacter sp. and Bizionia sp. (Fig. 3). 


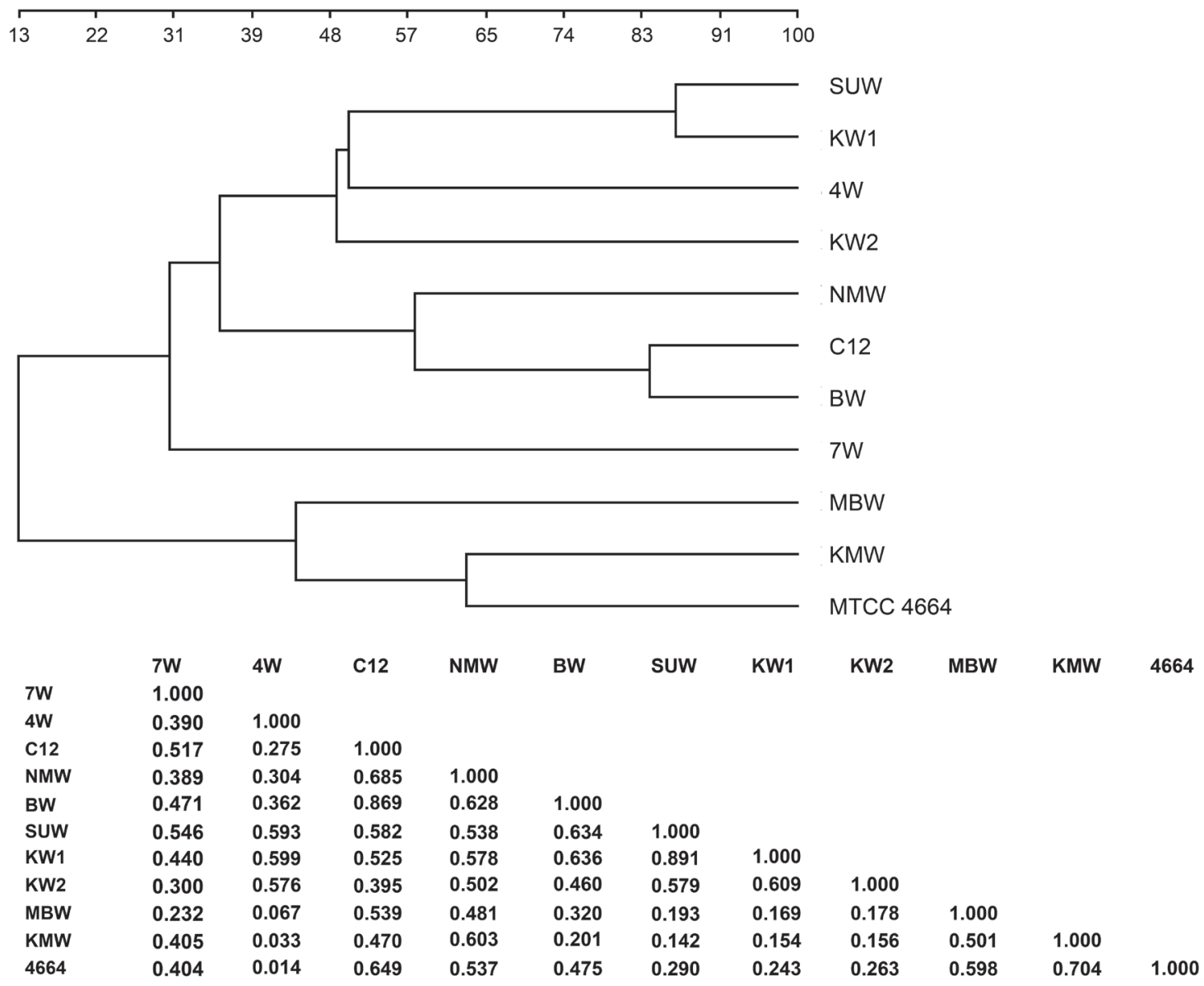

Fig. 2. Dendrogram derived from the UPGMA clustering of correlation coefficients based on the SDS-PAGE of whole-cell protein patterns of 10 Flavobacterial isolates along with standard culture (MTCC 4664).

The phenotypic characteristics of all the isolates are given in Table II. All the isolates were gram-negative rods with yellow-orange colored slimy colonies. The selected isolates were non-motile, asporogenic, indole-, citrate-, malonate- and MRVP-negative and catalasepositive. Except three isolates of Vitellibacter all the other isolates were positive for oxidase. All strains were negative for fermentation and hence, they are strictly aerobic. The isolates belonging to Vitellibacter and Formosa were not able to produce acids from any sugars while those belonging to Arenibacter genus were able to produce acid from many of the sugars. Vitellibacter sp. BW and two Formosa isolates were able to hydrolyse gelatin. The optimum growth of these marine organisms was at $\mathrm{pH}$ 7.0. However, some of the isolates could grow at $\mathrm{pH}$ 4.0. Arenibacter $\mathrm{sp}$. $4 \mathrm{~W}$ showed weak growth at $\mathrm{pH}$ 10.0. All the isolates were able to grow at $37^{\circ} \mathrm{C}$; however the isolates belonging to Vitellibacter showed better growth and pigmentation at $25^{\circ} \mathrm{C}$. All the isolates were found to be nonpathogenic as tested by haemolytic activity. With respect to antibiotic sensitivity of isolates, all the isolates were sensitive to most of the antibiotics tested. However, 5 of the isolates were resistant to tobramycin (data not shown) indicating that tobramycin could also be used in the media for selective isolation and to prevent contamination from other bacteria when used for carotenoid production.

SEM images of the bacteria give a clear image of the structural features of the bacteria. The SEM images of the different Flavobacteriaceae isolates are shown in Fig. 4. Isolates belonging to Vitellibacter were thin elongated rod-shaped bacteria without flagella or fimbriae. The isolates belonging to Formosa were short rods, while those belonging to Arenibacter were moderately long rods.

Production of yellow or orange pigments on agar plates has been used as one of the criteria for isolation of the members of the family Flavobacteriaceae. However, the overgrowth of non-pigmented bacteria, particularly from soil samples necessitates use of selective media for isolation of flavobacteria. As flavobacteria are known to be resistant to kanamycin, Flint (1985) suggested the use of kanamycin-containing medium for selective isolation of flavobacteria. In the present study when kanamycin-containing marine agar was used for isolation of bacteria from marine sources, the dominance of pigment producers in the media was observed. The pigment producing isolates were purified for further 
Table II

Phenotypic characteristics of the isolates.

\begin{tabular}{|c|c|c|c|c|c|c|c|c|c|c|}
\hline & 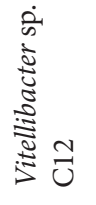 & 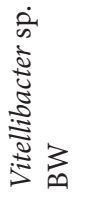 & 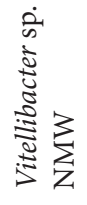 & 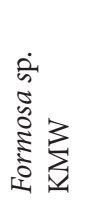 & 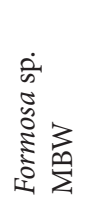 & 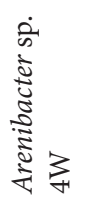 & 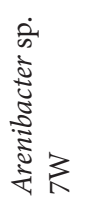 & 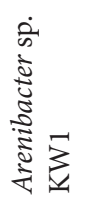 & 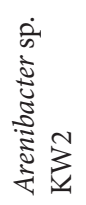 & 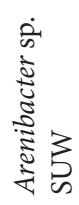 \\
\hline Gram reaction & - & - & - & - & - & - & - & - & - & - \\
\hline Morphology & Rods & Rods & Rods & Rods & Rods & Rods & Rods & Rods & Rods & Rods \\
\hline Oxidase & - & - & - & + & + & + & + & + & + & + \\
\hline Catalase & + & + & + & + & + & + & + & + & + & + \\
\hline MR/VP & $-/-$ & $-1-$ & $-1-$ & $-1-$ & $-1-$ & $-1-$ & $-1-$ & $-1-$ & $-1-$ & $-1-$ \\
\hline Indole & - & - & - & - & - & - & - & - & - & - \\
\hline $\mathrm{O} / \mathrm{F}$ & $-1-$ & $-1-$ & $-1-$ & $-1-$ & $-1-$ & $+1-$ & $+1-$ & $+/-$ & $+1-$ & $+/-$ \\
\hline Flexirubin production & + & + & + & + & + & - & - & - & - & - \\
\hline \multicolumn{11}{|l|}{ Acid from } \\
\hline Lactose & - & - & - & - & - & + & + & + & + & + \\
\hline Xylose, & - & - & - & - & - & + & + & + & - & + \\
\hline Maltose & - & - & - & + & + & + & + & + & + & + \\
\hline Fructose & - & - & - & - & - & + & + & + & + & + \\
\hline Dextrose & - & - & - & + & + & + & + & + & + & + \\
\hline Galactose & - & - & - & - & - & + & + & + & + & + \\
\hline Raffinose & - & - & - & - & - & + & + & + & + & + \\
\hline Trehalose & - & - & - & + & + & + & + & + & + & + \\
\hline Melibiose & - & - & - & - & - & + & + & + & + & + \\
\hline Sucrose & - & - & - & $\mathrm{w}$ & $\mathrm{w}$ & + & + & + & + & + \\
\hline L-Arabinose & - & - & - & - & - & - & - & - & - & - \\
\hline Mannose & - & - & - & + & + & - & - & - & - & - \\
\hline Inulin & $\mathrm{w}$ & $\mathrm{w}$ & $\mathrm{w}$ & $\mathrm{w}$ & $\mathrm{w}$ & + & + & + & + & + \\
\hline Sodium gluconate & - & - & - & - & - & + & + & - & + & + \\
\hline Glycerol & - & - & - & - & - & - & - & - & - & - \\
\hline Salicin & - & - & - & + & + & - & - & - & + & - \\
\hline Dulcitol & - & - & - & - & - & + & + & + & + & + \\
\hline Inositol & - & - & - & $\mathrm{w}$ & $\mathrm{w}$ & - & - & - & + & - \\
\hline Sorbitol & - & - & - & - & - & - & - & - & - & - \\
\hline Mannitol & - & - & - & - & - & - & - & - & - & - \\
\hline Adonitol & - & - & - & - & - & - & - & - & - & - \\
\hline Arabitol & - & - & - & - & - & - & - & + & - & + \\
\hline Erythritol & - & - & - & - & - & - & - & - & - & - \\
\hline a-Methyl-D-glucoside & - & - & - & - & - & - & - & - & + & - \\
\hline Rhamnose & - & - & - & - & - & + & + & + & + & + \\
\hline Cellobiose & - & - & - & $\mathrm{w}$ & $\mathrm{w}$ & - & - & - & - & - \\
\hline Melezitose & - & - & - & - & - & + & + & + & + & + \\
\hline a-Methyl-D-Mannlside & - & - & - & - & - & + & + & + & - & + \\
\hline Xylitol & - & - & - & - & - & + & + & + & + & + \\
\hline D-arabinose & - & - & - & - & - & + & + & + & + & + \\
\hline Sorbose & - & - & - & - & - & - & - & - & - & - \\
\hline$\beta$-galactosidase & - & - & - & - & - & - & - & - & - & - \\
\hline
\end{tabular}


Table II. Continued.

\begin{tabular}{|c|c|c|c|c|c|c|c|c|c|c|}
\hline & 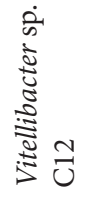 & 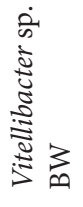 & 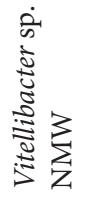 & 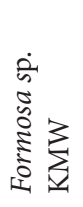 & 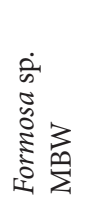 & 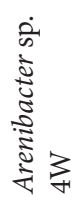 & 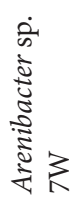 & 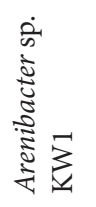 & 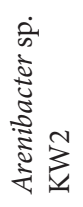 & 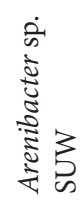 \\
\hline \multicolumn{11}{|l|}{ Hydrolysis of } \\
\hline Esculin & - & - & - & - & - & - & - & - & - & - \\
\hline Gelatin & - & + & - & + & + & - & - & - & - & - \\
\hline Starch & - & - & - & - & - & - & - & - & - & - \\
\hline Citrate Utilization & - & - & - & - & - & - & - & - & - & - \\
\hline Malonate Utilization & - & - & - & - & - & - & - & - & - & - \\
\hline \multicolumn{11}{|l|}{ Growth at $\mathrm{pH}$} \\
\hline 4.0 & - & $\mathrm{w}$ & - & + & - & $\mathrm{w}$ & - & $\mathrm{w}$ & $\mathrm{w}$ & + \\
\hline 7.0 & + & + & + & + & + & + & + & + & + & + \\
\hline 10.0 & - & - & - & - & - & $\mathrm{w}$ & - & - & - & + \\
\hline \multicolumn{11}{|l|}{ Growth at temperature } \\
\hline $25^{\circ} \mathrm{C}$ & + & + & + & + & + & + & + & + & + & + \\
\hline $37^{\circ} \mathrm{C}$ & + & + & + & + & + & + & + & + & + & + \\
\hline $50^{\circ} \mathrm{C}$ & - & - & - & $\mathrm{w}$ & $\mathrm{w}$ & - & - & - & - & - \\
\hline Haemolysis & - & - & - & - & - & - & - & - & - & - \\
\hline
\end{tabular}

+: Positive; -: Negative; W: Weak

characterization using phenotypic and molecular techniques like Random Amplified Polymorphic DNA (RAPD) finger printing $16 \mathrm{~S} r R N A$ gene sequencing.

RAPD is a relatively rapid PCR-based genomic fingerprinting method and is a useful tool for genome analysis in bacterial identification where isolates can be compared and grouped. Polymorphism between strains is detected as the difference between the patterns of amplified DNA fragments. In the present study the analysis of RAPD banding patterns of the isolates by dendrogram and cluster analysis indicated that the 10 isolates were in two major groups. Five isolates, which were later identified as Arenibacter sp. formed one group and the other 5 isolates later identified as either Vitellibacter sp. or Formosa sp. formed another group. The results indicated that genetic homogeneity between Vitellibacter sp. and Formosa sp. and their diversity from Arenibacter sp. under the Flavobacteriaceae family.

Whole-cell protein pattern analysis by SDS-PAGE and dendrograms obtained from numerical analysis is one of the techniques used for typing of bacterial species and grouping (Walia et al., 1988). In the present study analysis of whole cell protein from the different isolates using SDS-PAGE indicated that based on banding pattern the isolates can be clubbed into two major groups. However, grouping was not similar to grouping based on RAPD fingerprinting. Even the isolates belonging to same genera were in different groups, indicating that SDS-PAGE of whole cell protein is not a reliable tool for grouping of selected isolates.

The phenotypic characteristics of the bacterial isolates provide information about nutrient and environmental requirement for the growth of the organisms, and such information will be useful when the organisms used for exploiting their beneficial role. The phenotypic characteristics of the isolates indicated that they are able to use different sugars and optimum growth conditions were found to be $\mathrm{pH} 7.0$ and a temperature range of $25-37^{\circ} \mathrm{C}$.

Analysis of 16S rRNA gene sequences of the selected isolates indicated that they belong to three genera of Flavobacteriaceae, namely, Formosa, Vitellibacter and Arenibacter. Isolation and characterization of organisms belonging to these three genera from different sources has been reported. Two species of Formosa genus, Formosa algae KMM3553 (Ivanova et al., 2004) and Formosa agariphila (Nedashkovaskaya et al., 2006a) has been reported so far. F. algae isolated from degrading thallus of the brown alga Fucus evanescens was found to be light yellow pigmented and positive for gliding motility, catalase, urease and utilization of lactose and glycerol and oxidase negative (Ivanova et al., 2004), while F. agariphila isolated from green alga Acrosiphonia sonderi and from sea water was positive for gliding motility, oxidase, catalase and for sugar utilization. 


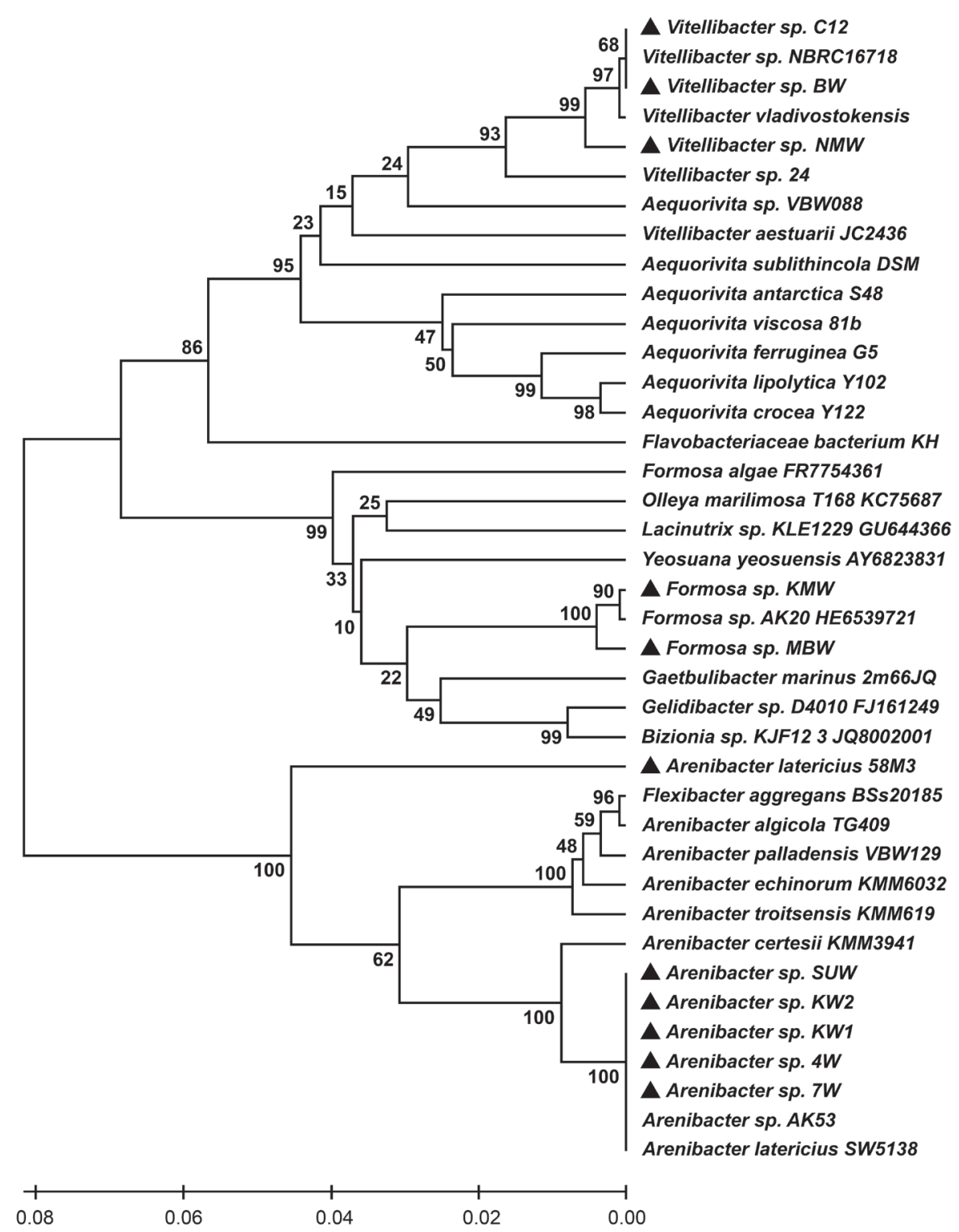

Fig. 3. Phylogenetic analysis of isolated cultures based on $16 \mathrm{~S}$ rRNA gene sequence.

The evolutionary history was inferred using the Neighbor-Joining method. The percentage of replicate trees in which the associated taxa clustered together in the bootstrap test (1,000 replicates) is shown next to the branches. The tree is drawn to scale, with branch lengths in the same units as those of the evolutionary distances used to infer the phylogenetic tree. All positions containing alignment gaps and missing data were eliminated only in pairwise sequence comparisons (Pairwise deletion option). Phylogenetic analyses was conducted by MEGA4 software. Representative sequences were obtained from GenBank and accession numbers given in parentheses. Flavobacterial cultures isolated are represented by

However, the two isolates of Formosa identified in the present study are phenotypically different indicating that they may be different species of Formosa.

The three species of Vitellibacter genus reported are Vitellibacter vladivostokensis KMM3516 (Nedashkovskaya et al., 2003a), Vitellibacter aestuarii JC2436 (Kim et al., 2010), and Vitellibacter soesokkakensis (Park et al., 2014). V. vladivostokenisis isolated from holothurian Apostichopus japonicus collected from Troitsa Bay in the Sea of Japan were yellow-orange pigmented, nonmotile, asporogenic, and strictly aerobic, gram-negative, oxidase- and catalase-positive bacteria. V. aestuarii isolated from tidal-flat sediment of Oi Island in Korea was found to be closely affiliated to V. vladivostokensis, with $96 \%$ sequence similarities to the type strain. The difference between the two strains was found to be $V$. vladistokensis being catalase-negative and susceptible to benzylpencillin but not to ampicillin and lincomycin (Kim et al., 2010). The Vitellibacter sp. isolated in the present study does not match exactly with the known Vitellibacter species reported and hence may be different species of Vitellibacter.

Presently six species of Arenibacter have been reported. They are Arenibacter latericius isolated from marine sediments (Ivanova et al., 2001), Arenibacter troitensis isolated from marine bottom sediments 


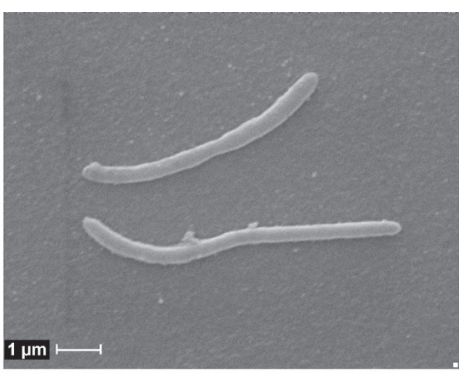

Vitellibacter sp. NMW

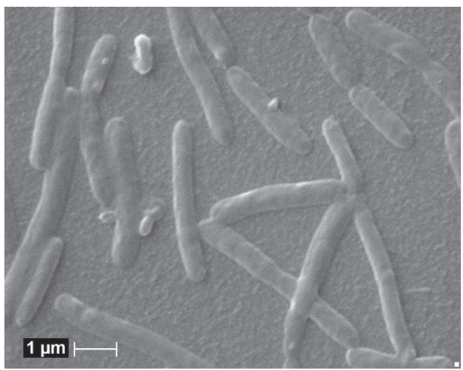

Arenibacter sp. KW1

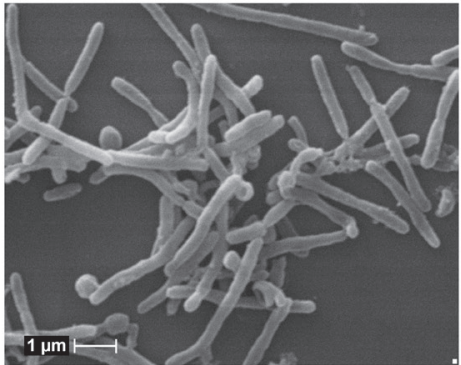

Arenibactersp. SUW

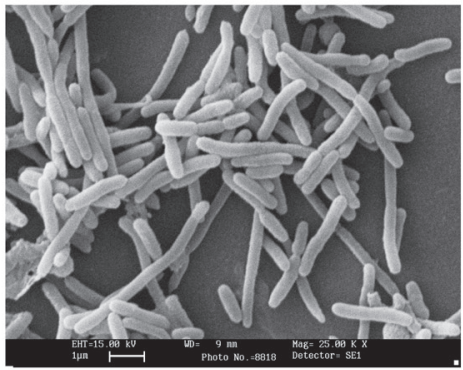

Arenibactersp. 7W

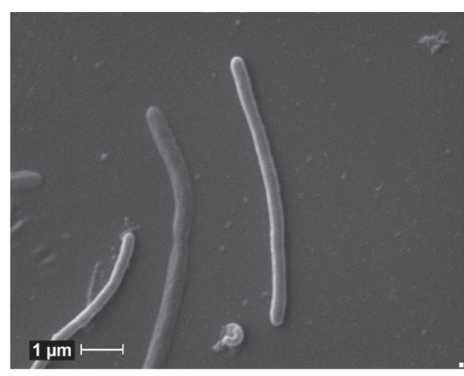

Vitellibacter sp. BW

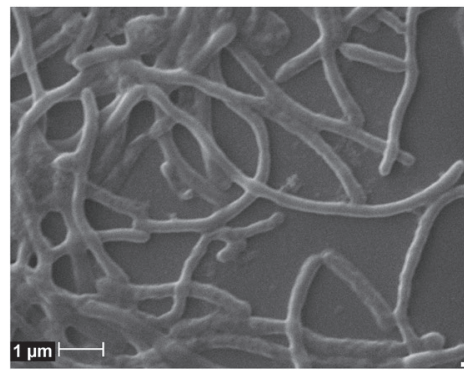

Vitellibacter $\mathrm{sp} . \mathrm{C} 12$

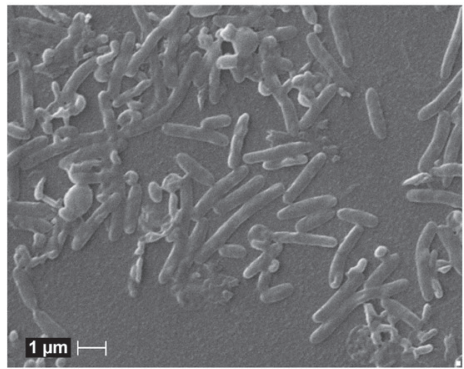

Arenibacter sp. 4W

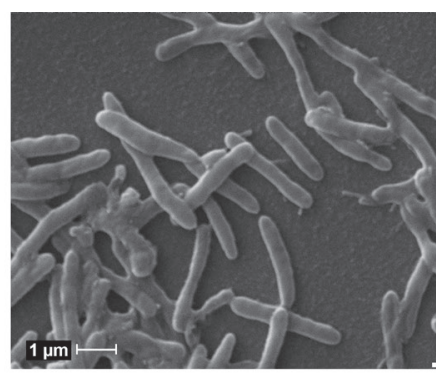

Arenibacter sp. KW2

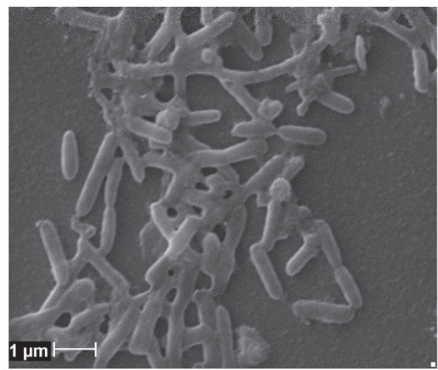

Formosa sp. MBW

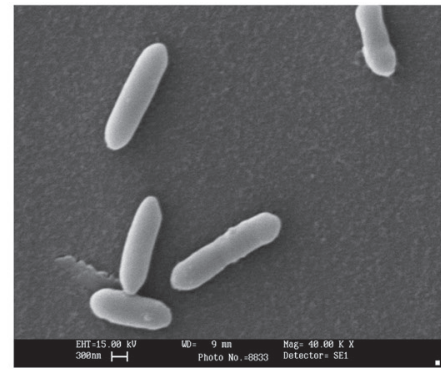

Formosa sp. KMW

Fig. 4. SEM image of Flavobacterial isolates depicting their structural morphology.

(Nedashkovskaya et al., 2003b), Arenibacter certessi isolated from green algae (Nedashkovskaya et al., 2004), Arenibacter palledensis isolated from green algae (Nedashkovskaya et al., 2006b), Arenibacter echinorum isolated from sea urchin (Nedashkovskaya et al., 2007) and Arenibacter nanhaiticus from marine sediment (Sun et al., 2010). Nedashkovskaya et al. (2007) compared the phenotypic characteristics of five species of Arenibacter and reported that they vary with respect to motility, production of acids from sugar, and gelatin hydrolysis. Three species (A. echinoum, A. latericius and A. palledensis) were able to produce acid from many of the sugars, and A.echinorum was able to utilize malonate and citrate, but not the other isolates. In the present study also all the Arenibacter isolates were able to produce acids from many of the sugars, but many other phenotypic characteristics did not match with the known isolates.

Extraction and characterization of carotenoids. The total carotenoid yield from different Flavobacterial isolates varied (Fig. 5). Significantly $(p<0.05)$ higher carotenoid yield ( $115.7 \pm 5.0 \mathrm{mg} / \mathrm{g}$ biomass) was observed in Vitellibacter sp. BW, followed by Arenibacter sp. $4 \mathrm{~W}(99.3 \pm 21.9 \mathrm{mg} / \mathrm{g}$ biomass). There was no specific dependency between carotenoid yield and the specific genus of the isolate. 


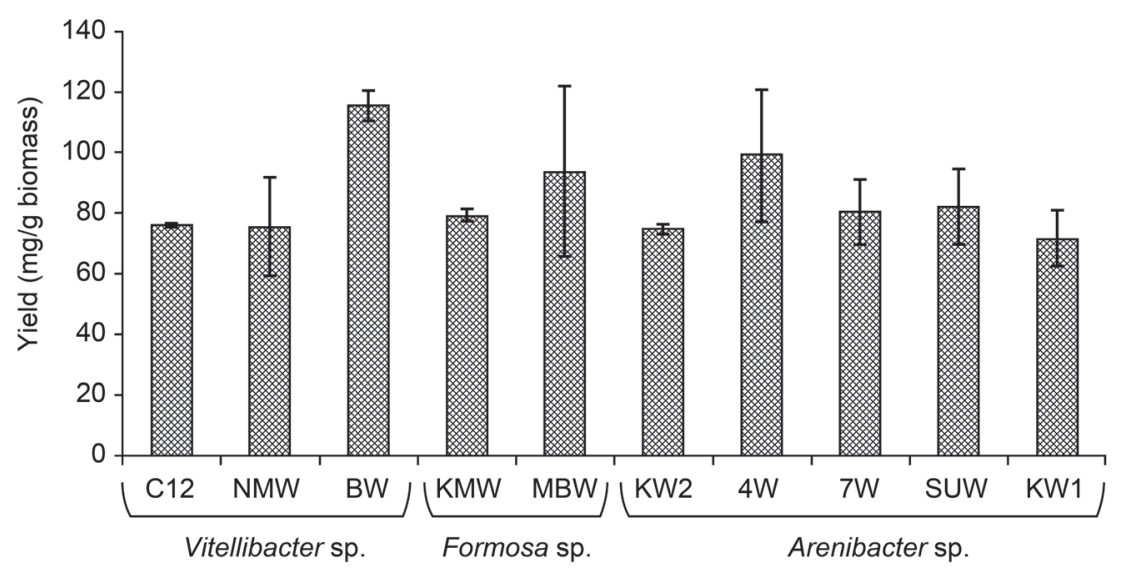

Fig. 5. Yield of crude carotenoid extract from different isolates.
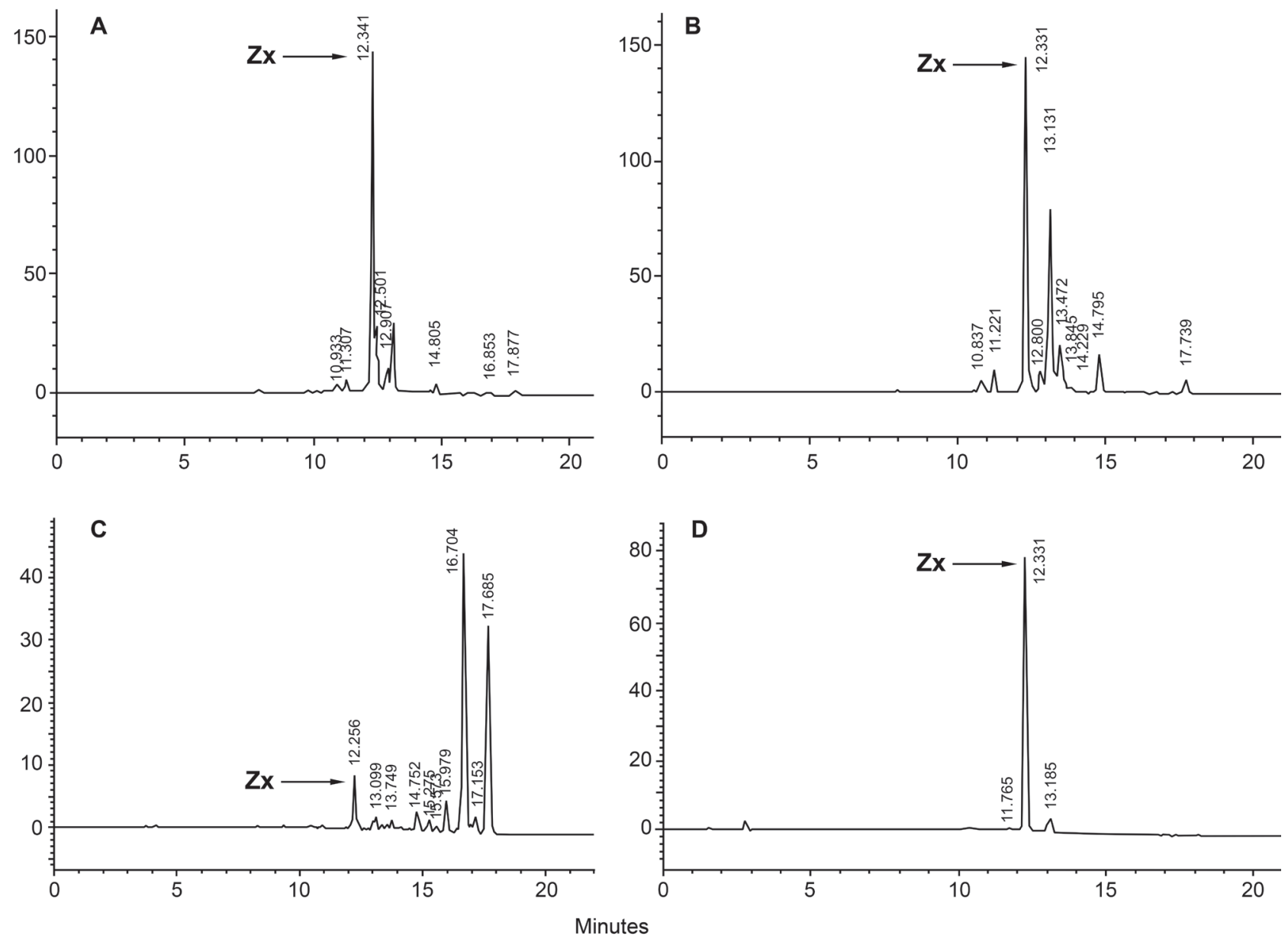

Fig. 6. HPLC profile of carotenoid extract of: (A) Vitellibacter sp. NMW; (B) Formosa sp. MBW; (C) Arenibacter sp. 4W; (D) Zeaxanthin $(\mathrm{Zx})$ standard.

The preliminary test for the identification of carotenoids in the crude carotenoid extract by TLC showed the presence of $\beta$-carotene and zeaxanthin. HPLC analysis of crude carotenoid extract from all isolates confirmed the presence of zeaxanthin and $\beta$-carotene, however, the concentration of two major carotenoids differed with the isolates. The typical HPLC profiles of one isolate from the three genera Vitellibacter NMW,
Formosa MBW and Arenibacter $4 \mathrm{~W}$ are given in figure $6 \mathrm{~A}, 6 \mathrm{~B}$ and $6 \mathrm{C}$ respectively and the HPLC profile of zeaxanthin standard in figure 6D. Significantly higher $(\mathrm{p}<0.05)$ zeaxanthin concentration of $61.4 \pm 8.3 \%$ was observed in the crude carotenoid extract from Formosa sp. KMW, followed by $59.6 \pm 18.8$ and $52.2 \pm 20.2 \%$ in carotenoid extract from Vitellibacter sp. BW and C12 (Fig. 7). The zeaxanthin content in the carotenoid extract 


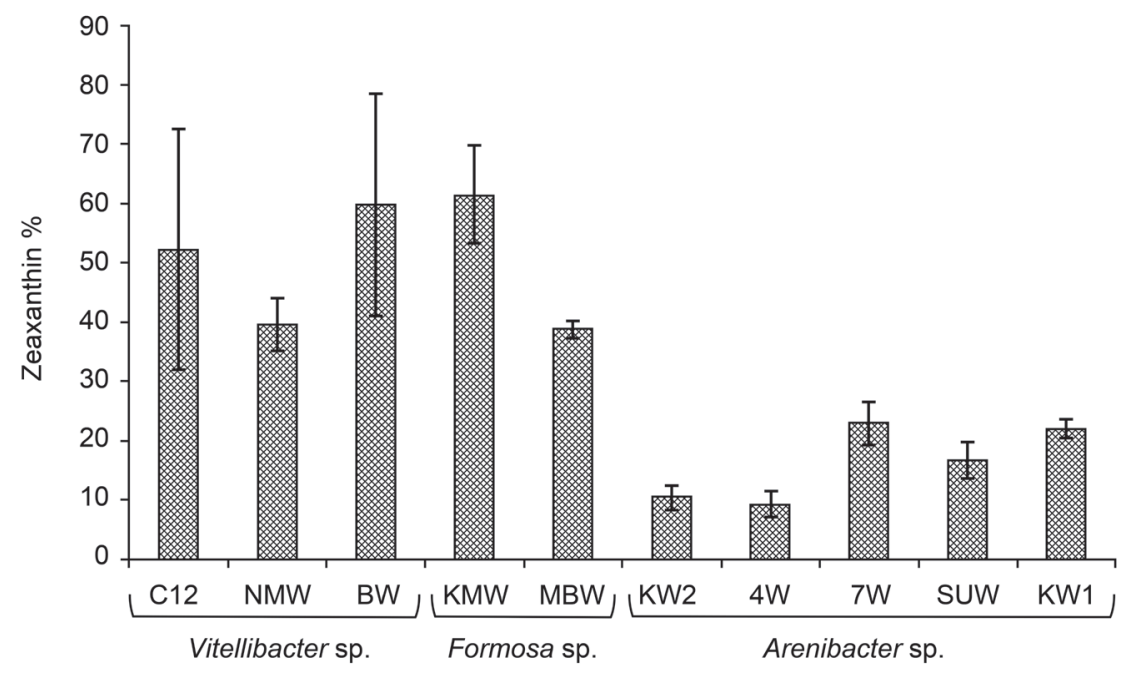

Fig. 7. Percentage of zeaxanthin in carotenoid extract from different Flavobacterial isolates.

from Arenibacter sp. was comparatively lower and was in the range of 9.2 to $23.0 \%$ of total carotenoid content.

Organisms belonging to Flavobacteriaceae are well known for the production of pigments. Flavobacterial isolates from soil and fresh water are known to produce flexirubin, a yellow-orange pigment, which is used as a taxonomic marker (Reichenbach et al., 1980). In the present study, only the isolates belonging to Vitellibacter and Formosa were found to produce flexirubin pigment (Table II). However, yellow pigmentation of marine isolates has been mainly attributed to carotenoids, particularly zeaxanthin (Stafsnes and Bruheim, 2013). Studies on the carotenoid production by Vitellibacter sp., Formosa sp. and Arenibacter sp. is lacking. As carotenoids have been shown to provide various health benefits, the isolates in the present study were tested for production of carotenoids with an aim to select a suitable isolate for further investigation on carotenoid production.

Studies on carotenoid production by Flavobacterium multivorum indicated that the organism produces zeaxanthin as the major carotenoid (Alcantara and Sanchez, 1999; Bhosale et al., 2004; Masetto et al., 2001). However, under specific nutrient condition such as the presence of inorganic salts and urea in the growth media interferes with the zeaxanthin biosynthesis pathway and results in the accumulation of intermediates such as canthaxanthin and $\beta$-carotene (Bhosale and Bernstein, 2004). The present study indicated that the isolates Vitellibacter sp. BW and $\mathrm{C} 12$ and Formosa sp. KMW can be successfully exploited as zeaxanthin producers.

In conclusion, the study resulted in selective isolation and identification of 10 isolates of carotenoid producing Flavobacteriaceae belonging to three genera of Arenibacter, Formosa and Vitellibacter. Since, not much information is present on these organisms and on the carotenoid production aspects of Vitellibacter sp., Formosa sp. and Arenibacter sp. an attempt has been made to study them. Vitellibacter sp. and Formosa sp. was found to produce higher amount of carotenoids compared to Arenibacter sp. Further, zeaxanthin was found to be the major carotenoid produced by Vitellibacter sp. and Formosa sp. These isolates have potential to be used for production of zeaxanthin in large scale that needs further studies on factors influencing zeaxanthin production by these isolates.

\section{Acknowledgments}

The authors wish to thank the Director, CSIR-CFTRI for encouragement and for the facilities provided. First author thanks Indian Council of Medical Research (ICMR) for the support in the form of fellowship.

\section{Literature}

Alcantara S. and S. Sanchez. 1999. Influence of carbon and nitrogen sources on Flavobacterium growth and zeaxanthin biosynthesis. J. Ind. Microbiol. Biotechnol. 23: 697-700.

Bauer A.W., M. Kirby, J.C. Sherris and M. Turck. 1966. Antibiotic susceptibility testing by a standardized single disk method. Ame. J. Clin. Pathol. 45: 493-496.

Bhosale P. and P.S. Bernstein. 2004. $\beta$-carotene production by Flavobacterium multivorum in the presence of inorganic salts and urea. J. Ind. Microbiol. Biotechnol. 31: 565-571.

Bhosale P., A.J. Larson and P.S. Bernstein. 2004. Factorial analysis of tricarboxylic acid cycle intermediates for optimization of zeaxanthin production from Flavobacterium multivorum. J. Appl. Microbiol. 96: 623-629.

Bone R.A., J.T. Landrum, Y. Cao, A.N. Howard and F.A. Calderon. 2007. Macular pigment response to a supplement containing meso-zeaxanthin, lutein and zeaxanthin. Nutri Metabol. 4: 12-19.

Carpenter K.L., C. van der Veen, R. Hird, I.F. Dennis, T. Ding and M.J. Mitchinson. 1997. The carotenoids beta-carotene, canthaxanthin and zeaxanthin inhibit macrophage-mediated LDL oxidation. FEBS Lett. 401: 262-266.

Chart H. 1994. Bacterial fractionation and membrane protein characterization, pp. 1-10. In: Chart H. (ed). Methods in practical laboratory bacteriology. CRC Press, Boca Raton. 
Decostere A. 2002. Flavobacterium columnare infections in fish: the agent and its adhesion to the gill tissue. Verh. K. Acad. Geneeskd. Belg. 64: 421-430.

Fautz E. and H. Reichenbach. 1980. A simple test for flexirubintype pigments. FEMS Microbiol. Lett. 8: 87-91.

Flint K. 1985. A note on a selective agar medium for the enumeration of Flavobacterium species in water. J. Appl. Bacteriol. 59: 561-566.

Ivanova E.P., Y.A. Alexeeva, S. Flavier, J.P. Wright, N.V. Zhukova, N.M. Gorshkova, V.V. Mikhailov, D.V. Nicolau and R. Christen. 2004. Formosa algae gen. nov., sp. nov., a novel member of the family Flavobacteriaceae. Int. J. Sys. Evol. Microbiol. 54: 705-711.

Ivanova E.P., O.I. Nedashkovskaya, J. Chun and A.M. Lysenko. 2001. Arenibacter gen. nov., new genus of the family Flavobacteriaceae and description of a new species, Arenibacter latericius sp. nov. Int. J. Sys. Evol. Microbiol. 51: 1987-1995.

Johnson E.A. and W.A. Schroeder. 1995. Zeaxanthin-containing compositions produced by Flavobacterium multivorum. US patent 5427783 A. June 27, 1995.

Kim B. S., O.S. Kim, E.Y. Moon and J. Chun. 2010. Vitellibacter aestuarii sp. nov., isolated from tidal-flat sediment, and an emended description of the genus Vitellibacter. Int. J. Sys. Evol. Microbiol. 60: 1989-1992.

Krinsky N.I. 1989. Antioxidant functions of carotenoids. Free Rad Biol Med. 7: 617-635.

Kumar S., M. Nei, J. Dudley and K. Tamura. 2008. Mega: A biologist-centric software for evolutionary analysis of DNA and protein sequences. Brief Bioinfor. 9: 299-306.

Laemmli U.K. 1970. Cleavage of structural proteins during the assembly of the head of bacteriophage T4. Nature 227: 680-684.

Manh H.D., Y. Matsuo, A. Katsuta, S. Matsuda, Y. Shizuri and H. Kasai. 2008. Robiginitalea myxolifaciens sp. nov., a novel myxolproducing bacterium isolated from marine sediment, and emended description of the genus Robiginitalea. Int. J. Sys. Evol. Microbiol. 58: 1660-1664.

Masetto A., L.B. Flores-Cotera, C. Diaz, E. Langley and S. Sanchez. 2001. Application of a complete factorial design for the production of zeaxanthin by Flavobacterium sp. J. Biosci. Bioeng. 92: 55-58.

McDougall L.A., W.H. Holzapfel, U. Schillinger, D.E. Feely and J.H. Rupnow. 1994. Scanning electron microscopy of target cells and molecular weight determination for bacteriocin produced by Lactococcus lactis D53. Int. J. Food. Microbiol. 24: 295-308.

Nedashkovskaya O.I., M. Suzuki, M.V. Vysotskii and V.V. Mikhailov. 2003a. Vitellibacter vladivostokensis gen. nov., sp. nov., a new member of the phylum Cytophaga-Flavobacterium-Bacteroides. Int. J. Sys. Evol. Microbiol. 53: 1281-1286.

Nedashkovskaya O.I., M. Suzuki, M.V. Vysotskii and V.V. Mikhailov. 2003b. Arenibacte rtroitsensis sp. nov., isolated from marine bottom sediment. Int. J. Sys. Evol. Microbiol. 53: 1287-1290.

Nedashkovskaya O.I., S.B. Kim, S.K. Han, A.M. Lysenko, V.V. Mikhailov and K.S. Bae. 2004. Arenibacter certesii sp. nov., a novel marine bacterium isolated from the green alga Ulva fenestrata. Int. J. Sys. Evol. Microbiol. 54: 1173-1176.

Nedashkovskaya O.I., S.B. Kim, M. Vancanneyt, C. Snauwaert, A.M. Lysenko, M. Rohde, G.M.Frolova, N.V. Zhukova, V.V. Mikhailov, K.S. Bae and others. 2006a. Formosa agariphila sp. nov., a budding bacterium of the family Flavobacteriaceae isolated from marine environments, and emended description of the genus Formosa. Int. J. Sys. Evol. Microbiol. 56: 161-167.
Nedashkovskaya O.I, M. Vancanneyt,I. Cleenwerck, C. Snauwaert, S.B. Kim, A.M. Lysenko, L.S. Shevchenko, K.H. Lee, M.S. Park, G.M. Frolova and others. 2006b. Arenibacter palladensis sp. nov., a novel marine bacterium isolated from the green alga Ulva fenestrata, and emended description of the genus Arenibacter. Int. J. Sys. Evol. Microbiol. 56: 155-160.

Nedashkovskaya O.I, S.B. Kim, A.M. Lysenko, K.H. Lee, K.S. Bae and V.V. Mikhailov. 2007. Arenibacter echinorum sp. nov., isolated from the sea urchin Strongylocentrotus intermedius. Int. J. Sys. Evol. Microbiol. 57: 2655-2659.

Nematollahi A., A. Decostere, F. Pasmans and F. Haesebrouck. 2003. Flavobacterium psychrophilum infections in salmonid fish. J. Fish Dis. 26: 563-574.

Nishino H., H. Tokuda, M. Satomi, P. Masuda, P. Bu, M. Onozuka, S. Yamaguchi, Y. Okuda, J. Takayasu, J. Tsuruta and others. 1999. Cancer prevention by carotenoids. Pure. Appl. Chem. 71: 2273-2278. Park S., K.C. Lee, K.S. Bae and J.H. Yoon. 2014. Vitellibacter soesokkakensis sp. nov., isolated from the junction between the ocean and a freshwater spring and emended description of the genus Vitellibacter. Int. J. Sys. Evol. Microbiol. 64: 588-593.

Rählert N., P.D. Fraser and G. Sandmann. 2009. A crtA-related gene from Flavobacterium P99-3 encodes a novel carotenoid 2-hydroxylase involved in myxol biosynthesis. FEBS Lett. 583: 1605-1610.

Reichenbach H., W. Kohl, A.B. Vetter and H. Achenbach. 1980. Flexirubin-type pigments in Flavobacterium. Arch. Microbiol. 126: 291-293.

Roberts R., J. Green and B. Lewis. 2009. Lutein and zeaxanthin in eye and skin health. Clinics. Dermatol. Neutra. Part II. 27: 195-201. Sajilata M.G., R.S. Singhal and M.Y. Kamat. 2008. The Carotenoid Pigment Zeaxanthin - A Review. Compr. Rev. Food Sci. Food Safety. 7: 29-49.

Sambrook J. and R.W. Russell. 2001. Molecular cloning: a laboratory manual. Cold Spring Harbor Laboratory Press, New York.

Schillinger U., N.M.K. Yousif, L. Sesar and C.M.A.P. Franz. 2003. Use of group-specific and RAPD-PCR analyses for 400 rapid differentiation of Lactobacillus strains from probiotic yogurts. Curr Microbiol. 47: 453-456.

Shindo K., K. Kikuta, A. Suzuki, A. Katsuta, H. Kasai, M.Y. Hirose, Y. Matsuo, N. Misawa and S. Takaichi. 2007. Rare carotenoids, (3R)-saproxanthin and (3R,2'S)-myxol, isolated from novel marine bacteria (Flavobacteriaceae) and their antioxidative activities. Appl. Microbiol. Biotechnol. 74: 1350-1357.

Sowmya R. and N.M. Sachindra. 2011.Carotenoids in aquatic resources: occurrence, recovery, application and biofunctions, pp. 75-118. In: Yamaguchi M. (ed). Carotenoids: Properties, Effects and Diseases. Nova Publishers, USA.

Stafsnes M.H. and P. Bruheim. 2013. Pigmented marine heterotrophic bacteria: occurrence, diversity and characterization of pigmentation, pp. 117-148. In: Kim S.K. (ed). Marine Biomaterials: Characterization, Isolation and Applications. CRC Press, Boca Raton. Statsoft. 1999. Statistics for windows. Statsoft Inc, Tulsa, USA.

Sun F., B. Wang, Y. Du, X. Liu, Q. Lai, G. Li, J. Luo and Z. Shao. 2010. Arenibacter nanhaiticus sp. nov., isolated from marine sediment of the South China Sea. Int. J. Sys. Evol. Microbiol. 60: 78-83. Walia T.M., T. Williamson, A. Kaiser and R. Tewari. 1988. Usefulness of protein patterns, serotyping and plasmid DNA profiles in the epidemiologic finger printing of P. aeruginosa. Eur. J. Clin. Microbiol. Infect Dis. 7: 248-255. 